\title{
"Mother" Matters: How changing language can compromise breastfeeding support
}

The lactation world is increasingly trying to avoid use of the word "mother." Even though the World Health Organization continues to consistently refer to "mothers" when advocating for those who give birth and breastfeed, many others are changing their language.

"Mother" is being replaced with terms such as "parent," "birthing parent" and "breastfeeding family." Invented terminology such as "menstruators" and "cervixhavers" is appearing, and "chestfeeding" is being paired with "breastfeeding." The intention is to promote inclusivity, but the result can be confusion and alienation.

When "parent" pops up in an article on breastfeeding, the reader doesn't know how it is being used. Does it refer to the father, the father-and-the-mother, or is it a code word for mother? Encountering illogical pairings such as "mothers and parents" and having to stop to decipher meaning takes the reader away from the point being made in the text.

Language can--and should--be customized in one-on-one counseling, such as talking about "babies" when dealing with twins, or avoiding references to sight with someone who is blind. However, when addressing a broader audience, it is vital to retain words that can be readily translated and easily understood: mother, mothering, and breastfeeding. The goal of communication cannot be to eliminate all possibility of offense. Trying to include everyone with broad terms can lead to ambiguity and even alienation. Consider the woman who adopts a baby and struggles heroically to induce lactation; she is not a "birthing parent," yet she deserves to be respected as a "mother in all other ways.

There are unintended consequences when "parent" is substituted for "mother." If outreach advertises "parent-to-parent support," does this invite the participation of fathers? What becomes of those who specifically wish to seek or provide "mother-tomother support"? The mother is vastly more important to a newborn than the father, but talking about "parents" obscures that distinction. For example, to protect newborns from COVID-19, it matters whether vulnerable infants are being separated from their biological mothers--or their "parents."

Confusing language is becoming an added obstacle to providing breastfeeding support, undermining the ability to effectively communicate with those who have the lowest rates of breastfeeding. The vast majority of women around the world are more concerned about keeping their children fed and alive than they are about being called by the "wrong" pronouns. In countries that outlaw homosexual practices, providing written materials containing pro-trans advocacy may risk imprisonment, and even death; ${ }^{1}$ are these risks being taken into account? 
Study of the mother-baby dyad has long been the established convention for research in the lactation field, and scientific research language is expected to be specific or to disclose exceptions. If transmen/transwomen have been included in a study, it is appropriate to identify them; but if the study talks only about "mothers," then it is dishonest to reference "parents" when reporting research, since this can subtly change meaning and outcomes. Accuracy about participants can be vital in matters such as safety precautions for co-sleeping, where it could be life-threatening for babies if research that has been done exclusively with breastfeeding mothers is misrepresented.

The medical, hormonal and psychological needs of trans-individuals are highly complex and require specialized care. While there are countless studies about the maternal lactating breast, an elegant organ steeped in evolution, there is little in the scientific literature studying chest-feeding. There is a need, as yet unmet, for resources addressing those specific needs. It is irresponsible, both to the transgender community and to mothers and babies, to encourage the misconception that we can simultaneously address different needs and safely ignore critical differences.

The current pressure to change language in order to serve everyone threatens to meet the needs of no one.

${ }^{1}$ International Lesbian, Gay, Bisexual, Trans, and Intersex Association (ILGA) December 2020 https://ilga.org/downloads/ENG_ILGA_World_map_sexual_orientation_laws_dec2020.p $\underline{\mathrm{df}}$

Human Rights Watch (HRW) March 2021 http://internap.hrw.org/features/features/lgbt_laws/; Human Dignity Trust (HDT) March 2021 https://www.humandignitytrust.org/lgbt-thelaw/map-of-criminalisation/

Marie Beam 